\title{
Novel microstructural strategies to enhance the electrochemical performance of $\mathrm{La}_{0.8} \mathrm{Sr}_{0.2} \mathrm{MnO}_{3-\delta}$ cathodes.
}

\author{
L. dos Santos-Gómez ${ }^{1}$, J. M. Porras-Vázquez ${ }^{1}$, E. R. Losilla ${ }^{1}$ and D. Marrero-López ${ }^{2}$ \\ ${ }^{1}$ Department of Inorganic Chemistry, University of Málaga, Campus de Teatinos s/n, 29071 Málaga, Spain \\ ${ }^{2}$ Department of Applied Physics I, Laboratory of Materials and Surfaces, University of Málaga, Campus de Teatinos s/n, \\ 29071 Málaga, Spain
}

Solid oxide fuel cells (SOFCs) are one of the most efficient technologies for direct conversion of fuels to electricity. $\mathrm{La}_{0.8} \mathrm{Sr}_{0.2} \mathrm{MnO}_{3-\delta}$ (LSM) is the cathode material most widely used in SOFCs [1], however, LSM exhibits high activation energy for oxygen reduction reaction (ORR) and low ionic conductivity, which limits its application at reduced temperatures. In this material the electrochemically active reaction sites are restricted to the triple-phase boundary (TPB) near the electrolyte/electrode interface, where the electrolyte, air and electrode meet. Different strategies have been investigated to enlarge the TPB area of LSM, such as the production of nanocrystalline powders by precursor routes, preparation of composites by infiltration methods and thin films [2-4].

Here we present and compare innovative procedures to extend the TPB of LSM in contact with yttria-stabilized zirconia electrolyte: i) nanocrystalline LSM films deposited by spray-pyrolysis on polished YSZ electrolyte; ii) the addition of polymethyl methacrylate microspheres as pore formers during the spray-pyrolysis deposition to further increase the porosity of these films and (iii) the deposition of LSM by spray-pyrolysis on porous backbones of $\mathrm{Zr}_{0.84} \mathrm{Y}_{0.16} \mathrm{O}_{1.92}$ (YSZ), $\mathrm{Ce}_{0.9} \mathrm{Gd}_{0.1} \mathrm{O}_{1.95}$ (CGO) and $\mathrm{Bi}_{1.5} \mathrm{Y}_{0.5} \mathrm{O}_{3-\delta}$ (BYO) electrolytes previously fixed onto the YSZ electrolyte.

The most remarkable peculiarity of this novel preparation method, compared to the traditional impregnation, is the formation of LSM thick film of $500 \mathrm{~nm}$ on the electrode surface (Fig. 1), which improves the electrical conductivity of the composite cathode. Thus, the optimization of this novel method would be an alternative to the classical infiltration with several advantages for the industry of planar SOFCs allowing the deposition of a wide variety of ceramic films over large areas with more uniform distribution of the catalyst, lower cost and only
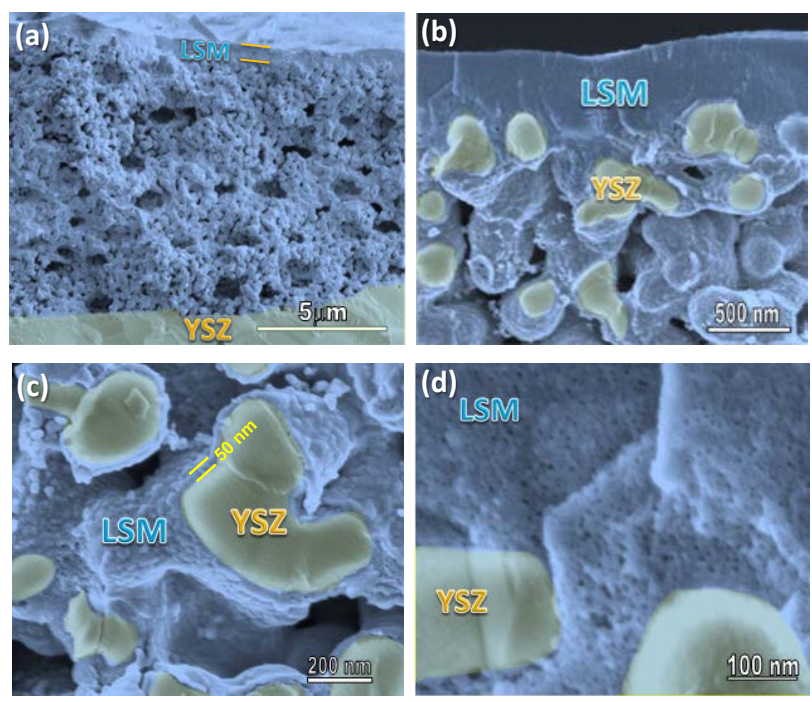

Fig. 1. SEM images of the cross-section of LSM cathodes deposited by spray-pyrolysis on YSZ backbone, showing a YSZ backbone of $10 \mu \mathrm{m}$ of thickness (a) with well adhered LSM coating on the surface of $Y S Z$ (b,c and d). A porous superficial layer of LSM of $500 \mathrm{~nm}$ of thickness is formed acting as current collector and improving the conductivity of the electrode. one deposition step is required to form the electrode.

The morphology and electrochemical performance of the electrode have been investigated by scanning electron microscopy and impedance spectroscopy. Very low values of area specific resistance were obtained ranging from $1.4 \Omega \mathrm{cm}^{2}$ for LSM deposited on polished YSZ to $0.06 \Omega \mathrm{cm}^{2}$ for LSM deposited onto BYO backbone at a measured temperature of $650^{\circ} \mathrm{C}$. This electrodes exhibit high performance even after annealing at $950{ }^{\circ} \mathrm{C}$ making them interesting for applications at intermediate temperatures.

Keywords: Fuel cells; $\mathrm{La}_{0.8} \mathrm{Sr}_{0.2} \mathrm{MnO}_{3-\delta}$; spray-pyrolysis, microstructure, impedance spectroscopy.

\section{References}

[1] D. Marrero-López, L. dos Santos-Gómez, J. Canales-Vázquez, F. Martín, J.R. Ramos-Barrado, Electrochimica Acta, 134 (2014) 159-166.

[2] D. Beckel, A. Bieberle-Hütter, A. Harvey, A. Infortuna, U.P. Muecke, M. Prestat, J.L.M. Rupp, L.J. Gauckler, J. Power Sources 173 (2007) 325-345.

[3] Y. Huang, J.M. Vohs, R.J. Gorte, Fabrication of SOFC Electrodes by Impregnation Methods In Advances in Electronic and Electrochemical Ceramics, 179, John Wiley \& Sons, Inc, Hoboken, NJ, USA, 2006.

[4] S.P. Jiang, Mater. Sci. Eng. A 418 (2006) 199-210. 